\title{
QUALITATIVE ANALYSIS OF PROJECT RISK
}

\author{
KREMLJAK, Z[vonko]
}

\begin{abstract}
In the paper the research on decision-making in highrisk conditions is presented. The results are important within strategic management, research and development management and industrial engineering. Risk assessment, risk management and qualitative project risk analysis also represent areas for development of projects. The main motivation is to create tools and techniques which help us to make better decisions. One of the most important steps to make excellent decisions regarding projects is qualitative analysis of project risk as described.

Key words: risk, risk management, risk handling, qualitative analyses, project risk
\end{abstract}

\section{INTRODUCTION}

A difficult part of the risk management process is data gathering. Techniques provide a means for collecting riskrelated data from subject-matter experts and from people who are intimately involved with the various aspects of the program. It relies on "expert" judgment to identify and analyze risk events, develop alternatives and provide "analyzed" data. It is used almost exclusively in a support role to help develop technical data, such as probability and consequences/impacts information, required by a primary risk assessment technique. It can address all the functional areas that make up the critical risk areas and processes and can be used in support of risk handling. Expert judgment is a sound and practical way of obtaining necessary information that is not available elsewhere or practical to develop using engineering or scientific techniques. However, interviewers should be aware that expert opinions may be biased because of over-reliance on certain information and neglect of other information; unwarranted confidence; the tendency to recall most frequent and most recent events; a tendency to neglect rare events; and motivation (Boyd, 2011; Holmes, 2002).

Lessons learned and historical information about the risk associated with programs that are similar to the new system to identify the risk associated with a new program. It is normally used to support other primary risk assessment techniques, e.g., Product (WBS) Risk Assessment, Process Risk Assessment, etc. The technique is based upon the concept that "new" programs are originated or evolved from existing programs or simply represents a new combination of existing components or subsystems. This technique is most appropriate when systems engineering and systems integration issues, plus software development, are minimal. A logical extension of this premise is that key insights can be gained concerning aspects of a current program's risks by examining the successes, failures, problems and solutions of similar existing or past programs. This technique addresses all the functional areas that make up the critical risk areas and processes (Byrd \& Cothern, 2000; Grey, 1995).

The first step in this approach is to select or develop a baseline comparison system (BCS) that closely approximates the characteristics of the new system/equipment to as low a level as possible and uses the processes similar to those that are needed to develop the new system. For processes, industry- wide best practices should be used as a baseline. Relevant BCS data are then collected, analyzed and compared with the new system requirements. The BCS data may require adjustment to make a valid comparison. The comparisons can be a major source of risk assessment data and provide some indication of areas that should be investigated further.

\section{QUALITATIVE PROJECT RISK ANALYSIS}

\subsection{Inputs}

We identify the following levels of qualitative project risk analysis (Chinbat, 2009):

- Identified risks - risks discovered during the risk identification process are evaluated along with their potential impacts on the project.

- Project status - the uncertainty of a risk often depends on the project's progress through its life cycle. Early in the project, many risks have not surfaced, the design for the project is immature and changes can occur, making it likely that more risks will be discovered.

- Project type - projects of a common or recurrent type tend to have better understood probability of occurrence of risk events and their consequences. Projects using state-of-theart or first-of-its-kind technology - or highly complex projects - tend to have more uncertainty.

- Data precision - precision describes the extent to which a risk is known and understood. It measures the extent of data available, as well as the reliability of data. The source of the data that was used to identify the risk must be evaluated.

- Scales of probability and impact - these scales are to be used in assessing the two key dimensions of risk; probability and consequences.

- Assumptions - assumptions identified during the risk identification process are evaluated as potential risks (***, 2002).

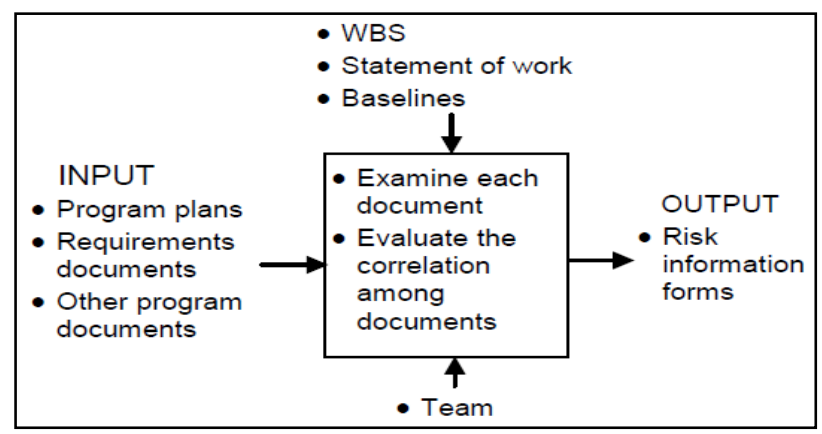

Fig. 1. Plan evaluation technique input and output

\subsection{Outputs}

- Overall risk ranking for the project - risk ranking may indicate the overall risk position of a project relative to other projects by comparing the risk scores. It can be used to assign personnel or other resources to projects with 
different risk rankings, to make a benefit-cost analysis decision about the project or to support a recommendation cancellation.

- List of prioritized risks - risks and conditions can be prioritized by a number of criteria. These include rank (high, moderate and low) or WBS level. Risks may also be grouped by those that require an immediate response and those that can be handled at a later date. Risks that affect cost, schedule, functionality and quality may be assessed separately with different ratings. Significant risks should have a description of the basis for the assessed probability and impact.

- List of risks for additional analysis and management - risks classified as high or moderate would be prime candidates for more analysis, including quantitative risk analysis and for risk management action (Conrow, 2000).

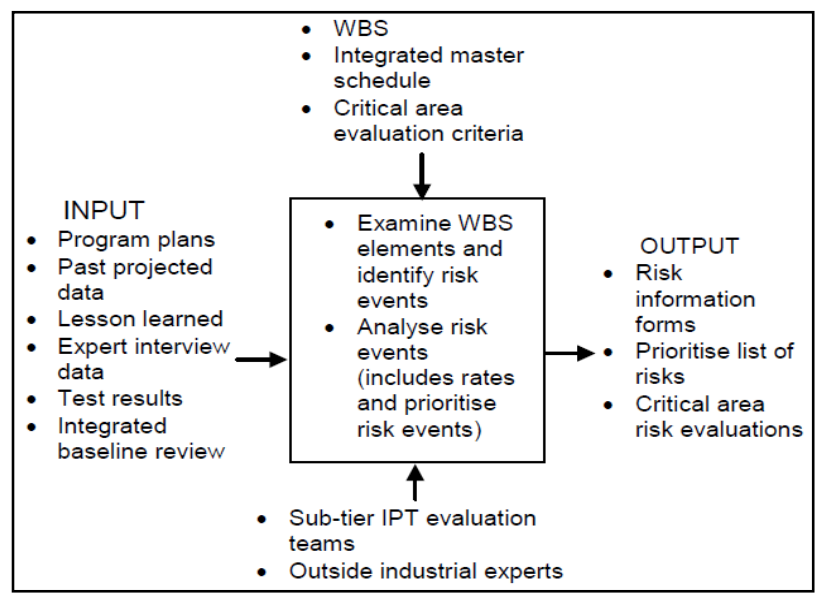

Fig. 2. Schedule risk assessment technique input and output

\section{TOOLS AND TECHNIQUES FOR QUALITATIVE PROJECT RISK ANALYSIS}

- Risk probability and impact - risk probability and risk consequences may be described in qualitative terms such as very high, high, moderate, low and very low. Risk probability is the likelihood that a risk will occur. Risk consequences are the effect on project objectives if the risk event occurs. These two dimensions of risk are applied to specific risk events, not to the overall project. Analysis of risks using probability and consequences helps identify those risks that should be managed aggressively (Beneplanc \& Rochet, 2011; Schuyler, 2001).

- Probability/impact risk rating matrix - a matrix may be constructed that assigns risk ratings (very low, low, moderate, high and very high) to risks or conditions based on combining probability and impact scales. Risks with high probability and high impact are likely to require further analysis, including quantification and aggressive risk management. The risk rating is accomplished using a matrix and risk scales for each risk (Vose, 2000).

- Project assumptions testing - identified assumptions must be tested against two criteria: assumption stability and the consequences on the project if the assumption is false. Alternative assumptions that may be true should be identified and their consequences on the project objectives tested in the qualitative risk-analysis process.

- Data precision ranking - qualitative risk analysis requires accurate and unbiased data if it is to be helpful to project management. Data precision ranking is a technique to evaluate the degree to which the data about risks is useful for risk management. It involves examining extent of understanding of the risk, data available about the risk, quality of the data, reliability and integrity of the data.
Software tools display user's risk simulation results fully integrated with native Gantt charts (Fig. 3). New bars indicate the range of possible values for uncertain variables, and display sensitivity and critical index information.

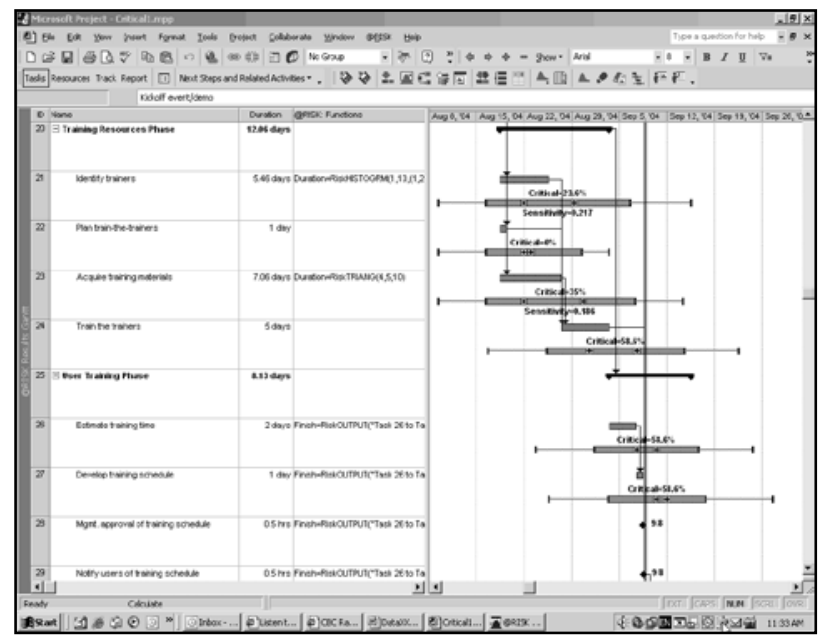

Fig. 3. Integrated risk results in the Gantt chart

\section{CONCLUSION}

In projects whose results are not only tangible resources but also capabilities, qualitative risk assessment is important. Qualitative risk analysis is a process of evaluating influence and certainty of recognized risks. Risks are arranged according to their potential influence on project goals. Qualitative risk analysis is one of the ways to define importance of treatment of individual risks and managing reaction to risk. Time aspect can rather increase the importance of risk. So, complete developed methodology is the main contribution to the field.

Assessing the quality of available information can also help manage the assessment. For qualitative risk analysis one must assess the probability and consequences of risk with established methods and tools for qualitative analysis. Decision-making in high-risk conditions is becoming a common area for research within strategic management, organizational theory, research and development management and industrial engineering.

\section{REFERENCES}

Beneplanc, G. \& Rochet, J.-C. (2011). Risk Management in Turbolent Times. Cary: Oxford University Press

Boyd, R. (2011). Fatal Risk. Hoboken: John Wiley \& Sons.

Byrd, D. M. \& Cothern, C. R. (2000). Introduction to Risk Analysis: A Systematic Approach to Science-Based Decision Making. ABS Consulting

Chinbat, U. (2009). Using simulation for reducing risk of a mining optimization project. Int. Journal of Simulation Modelling, Vol. 8, No. 3, p. 166-177

Conrow, E. H. (2000). Effective risk management. AIAA (American Institute of Aeronautics \& Ast)

Grey, S. (1995). Practical risk assessment for project management. Chicester: John Wiley \& Sons

Holmes, A. (2002). Risk Management. Oxford: Capstone Publishing

***Project Management Institute. (2002). A guide to the project management body of knowledge. Pennsylvania, Newton Square: Project Management Institute

Schuyler, J. (2001). Risk and Decision Analysis in Projects (Cases in project and program management series). Pennsylvania, Newton Square: Project Management Institute

Vose, D. (2000). Risk analysis: a quantitative guide. Chicester: John Wiley \& Sons 